\title{
Demographic change in European towns 2001-11: a cross-national multi-level
}

analysis.

Ian Smith, Department of Accounting, Economics and Finance, University of the West of England, Bristol

Key words: Europe, towns, spatial development, multi-level regression, migration

The unique contribution of this paper is to empirically compare and contrast demographic change in settlements with a population between 5000 and under 50000 (defined as towns) across different national urban systems in Europe with common definitions for the first time. The analysis uses a new data set based on harmonised small area data and harmonised morphological definitions of what a town is. The paper hypothesises firstly that a general model of demographic growth can be applied across national urban systems and secondly that regional demographic change is a significant predictor of demographic change in towns nested within those regions within this generalised model. A fixed effect multi-level regression analysis tests the importance of town-level and regional factors amongst towns from five national systems but also within two individual national urban systems. The findings suggest that national context still matters and within some national systems, regional context also strongly predicts demographic change in towns. 


\section{Introduction}

Towns are an important part of the urban fabric of Europe. Although often associated with the economic health of rural areas (van Leeuwen and Rietveld 2011 or Powe et al 2009), European towns are found in many different types of regions (not just rural ones). Yet this category of settlement is largely invisible in official statistics. This invisibility led Roger Brunet $(1997, \mathrm{p} 188)$ to describe the European town as "... an unidentified real object". One problem of studying these settlements arises from a general lack of consensus as to what constitutes a town in the first place. Studies for a single national urban system have focused on outlining the characteristics of towns (for example Shepherd 2009, Matlovic and Bernasovsky 2002, or Mario and Christophe 2012). However, these differences in definition (for example in relation to population size thresholds) make it very difficult to directly compare findings about towns across and between their national contexts. Part of the confusion comes down to linguistic uses of the term 'town' and differing administrative definitions of what constitutes a town (in Eastern Europe in particular). This paper takes a harmonised morphological perspective in defining what constitutes a town that is applicable across national urban systems. A town is defined as a contiguous urban settlement that agglomerates between 5000 and 50000 inhabitants within this contiguous area and that records a population density of greater than 300 persons per square kilometre. This is a morphological class of settlement in which $25 \%$ of Europe's population live.

The paper will offer evidence from the analysis of a new harmonised data-set for towns in Europe. The harmonised data-set used in this paper is based on a common morphological definition of a town and derives town-level demographic characteristics from small area data for five European countries. The analysis examines whether towns are following a common model of demographic growth across the five countries. The paper considers two dimensions of demographic change: natural change and change due to net-migration and it will empirically test a series of potential correlates across five national urban systems using multi-level regression models.

\section{Why do towns grow/decline?}

Based on what literature there is on towns, there are two basic explanations of why towns get bigger or smaller. The first set of explanations focus on the inherent characteristics of the town itself. The second set of explanations focus on the regional context in which a town is located. In developing a set of hypotheses on demographic change the paper considers both views.

The existing literature conceptualises the 'wider' context for towns in two ways: either it is conceptualised as a being located in a given national urban system (e.g. Slovakian towns or English towns); or towns are given the characteristics of the wider functional region (such as a local labour market) in which they are located. Hinderink and Titus (2002, p384) referring to towns in Asia, the Americas and Africa observed that small town development is more dependent upon their national and regional economic and policy contexts than on the characteristics of the towns themselves. Specifically they relate small town performance to the availability of resources, population density and market accessibility as proxies for their regional context. Thus the performance of towns is observed as associated with regional 
characteristics albeit that Hinderink and Titus (2002) do not draw a clear distinction between functional regional or arbitrary administrative regions.

Bretagnolle et al (1999) stress the importance of the national urban system. Taking a very long time horizon (400 years) and looking at complete national urban systems, Bretagnolle et al (1999) would claim that long term settlement growth is constrained by the urban system in which the town in located. Short term development in any given town might temporarily exceeds a long-term growth trajectory that might be expected because of the town's location within a settlement hierarchy. However in the long term 'super-normal' growth becomes re-distributed if the town's size comes to be located outwith of a lognormal distribution. Thus settlement systems are self-organising with a tendency to enforce a hierarchical distribution of population across the system. In this extreme position the characteristics of the town are not pertinent (although they might be in the short term).

However in this work the relationship between town development and its wider context is reported as a statistical pattern rather than as a series of processes. More general work on regional development processes discusses the processes by which 'rural' areas (not necessarily or explicitly noted as towns) interact with larger metropolitan areas that are nearby. This would be the case of seeing the key context as the functional region in which a town sits. Partridge et al (2007) emphasise the importance of proximity to larger metropolitan areas in their work on rural economic development in Canada. These researchers considered the impacts of spread and backwash (derived from Myrdal 1963) effects on rural areas around metropolitan areas. Here backwash is a general adverse effect of trade and commuting patterns from rural peripheries being attracted towards large urban centres whilst spread refers to a process whereby peripheral places (such as accessible towns) grow because of their proximity to larger urban centres. The econometric work of Partridge et al (2007) supported the idea that distance from a metropolitan centre was an important factor that helped predict rates of development in the rural fringe. Rural areas (and the towns within them) further away from metropolitan centres grew less.

Although the insights of Partridge et al (2007) are derived from the Canadian urban system there is no particular reason to believe that the European towns close to metropolitan areas would not also experience some kind of population uplift effect from being close to larger urban areas. Population growth associated with small towns in peri-urban locations has been explored by Renaud-Hellier (2002) for Dijon (France) where a similar process of population growth as a peri-urban fringe was observed. European peri-urbanisation is rarely report with respect to changes in towns. There is however an established literature on the selective migration processes covered by the title of counter-urbanisation that impact on places on the periphery of metropolitan regions. Hall and Hay (1980) have described urbanisation taking place in different phases of growth and decline of central urban versus peripheral areas (where small towns are associated with the hinterland to large cities), then counter-urbanisation can be associated with the later phases of urban development (assuming a linear progression of phases). Thus if it is possible to systematically identify smaller settlements within metropolitan areas it would be possible to see whether ex-urbanisation or counter-urbanisation did in fact impact on towns in the metropolitan fringe. 
Again emphasising the importance of functional (regional) context, Champion and Shepherd (2006) link the demographic dynamic of areas with small towns in them (rural areas) to processes of counter-urbanisation in England. Thus small towns in rural areas are part of a broader circuit of movement whereby working households with adults in their 40s and older look to move to rural locations (including smaller towns) replacing adults in the 20s leaving rural areas to look for education and jobs. Thus the spread and backwash effects become associated with the choices of selective fractions of the population as to where they live and the residential amenity associated with this choice. So we might expect to see differential processes relating to counter-urbanisation impacting on towns within wider regional urban systems.

The work of Congdon and Shepherd (1986) looked at modelling population changes in small English urban areas (such as towns). These authors anchor their work in the consideration of counter-urbanisation within the English urban system. In reviewing theories of small town growth, Congdon and Shepherd (1986, p1302) set out five processes underpinning the demographic dynamics of small towns in England: people led selective migration; employment dispersal and restructuring; the extension of accessibility to commuting; changes in housing availability (and tenure); and finally policy-led dispersal. These complex stories of relative growth and decline place the process of change within small English towns within a general process of counter-urbanisation but they strongly link population growth to changes in the location of work (and jobs). Thus these authors discuss whether population growth in English towns is led by changes in employment that subsequently attract people to live or whether towns are attractive places to live that subsequently attract the movement of employment (either as a residential economy or productive jobs). However in the case of people-led explanations of growth the explanation lies in the attractiveness of towns as places to live that are consumed selectively by wealthy working or retired householders. In summary, a town's capacity to maintain or growth its population depends upon local labour market conditions.

Work based on case studies has come to alternative conceptualisations of what constitutes the successful/unsuccessful small town. This work tends to stress the characteristics of the town itself. For example, Knox and Mayer $(2009$, p13) offer up an implicit set of factors that underpin success and decline for small towns in Europe and North America that might be measured in terms of population change. Knox and Mayer's review of case study narratives of towns in Europe and North America relate success of towns to their 'health' covering equity, environment, economy and culture and community. Thus for Knox and Mayer the notion of the 'economy' is a matter of considering the particular mix of economic activity (by industrial classification), the range of shopping opportunities, the culture of entrepreneurship and accessibility to employment rather than the concerns of economic competitiveness. However this is a set of ideas that requires us to think about the amenity value of towns on top and to understand 'amenity' related migration (such as that linked to retirement) (Gosnell and Abrams 2011).

Thus the literature posits a number of processes associated with population growth in towns. Firstly there is the milieu development model whereby population change in towns is framed by the labour market conditions in that town (the employment-led model). However there is also a strong expectation that town growth is framed by the regional 
context of the town or indeed by processes of distributed growth across an urban systems as a whole (that may extend way beyond an immediate 'region'). In considering the processes of backwash and spread it is the distance from major urban centres that is key to understanding the regional context albeit that this context may need to be understood in terms of accessibility rather than in distance alone. The processes of backwash and spread might not be related to the movement of working age adults. However employment-led development was only one of the drivers of demographic change in towns according to Congdon and Shepherd (1986). People-led development was linked to the notion of towns as amenity rich locations that are both attractive places to live in but also are places where there is sufficient housing (or at least housing development possibilities) for (often) selective net migration by wealthy net migrants. Thus there is a requirement to introduce measures of environmental value into the statistical model.

Thus the existing literature does not posit an explicit hypothesis as to whether changes in towns are likely to be different when comparing one national system to another. The existing literature as it has focussed primarily on national urban systems has tended to focus on what differentiates towns (and the changes associated with them) within a national urban system. The existing literature does however note that the broader economic context impacts on change in small towns. This can be either framed by proximity to larger cities (increasing population and changing employment profile) or being located in a rural region (declining population and fragile employment prospects). The general proposition is that the existing literature would expect change in towns to mirror that of the region in which they are located.

\section{Constructing a data-set of European small towns}

In order to compare towns there is a need to construct a harmonised data-set of comparable things. The starting point for such an exercise is a harmonised set of settlement boundaries. Russo et al (forthcoming) outlines the geomatic process of creating boundaries of contiguous urban areas based on GEOSTAT grid data ( $1 \mathrm{~km}$ square) with a population estimate for 2006. However small area data from sources such as Censuses of Population are organised in terms of statistical small areas. Thus the technical problem in generating town-level data is how to relate the grid-based polygons representing the contiguous settlement boundaries with the small area geographies that have been used to organise census and administrative data across Europe. The aim of constructing such a data-set was to see how an urban audit exercise might be extended to the range of smaller places.

In order to make the spatial link, the grid-based contiguous polygons were intersected with the small area polygons (associated with census and administrative small area data). How the small area data was to be apportioned depended upon the geographic characteristics of the small area polygons. Table 1 outlines the characteristics of the small area data units for six European countries. The table outlines the number of spatial units for the countries under consideration. Only the spatial units associated with England and Wales (lower super output areas) related to a geography designed to create relatively homogenous statistical units. The output units for England and Wales were relatively small in population terms (averaging just over 1000 residents) but they also had the lowest coefficient of variation of the six statistical nations. In the five other countries the small areal units related to the 
geography of local government in each country (municipalities). As such these municipal units were relatively homogenous in terms of the geographic area but demonstrated relatively high coefficients of variation with respect to population. In order to take this into account a method of proportioning small area populations was adopted in the countries where small area units were defined relative to the geography of local government. In the case of England and Wales a simple aggregation method was used.

[Table 1 about here]

[Table 2 about here]

The process of intersecting and aggregating generated a geography of intersected fragments that is described in Table 2. The geomatic process of identifying contiguous urban areas identified 2145 settlements meeting the morphological definition of a town (population between 5,000 and 50,000 and a population density greater than 300 persons per $\mathrm{km} 2$ ). The process of geomatically linking these settlement boundaries to the geographic units associated with small area data for these countries allowed us to construct a town database for 1978 towns. In the case of Belgium and the United Kingdom the research team was only able to put together a complete attribute data-set for Flanders and England and Wales respectively. Table 2 demonstrates the average population size estimated by the population grid and the estimate of population size based on the proportional aggregation of small area units. The proportioning factor used to make this estimation of total population was used to estimate all the areal attributes based on small area data-sets. For all countries with the exception of England and Wales, the attribute estimation was based on aggregating (on average) between one and four areal units. In England and Wales where census output areas were used, a small town on average intersected with 12.3 output areas (for a longer outline of the aggregation process see (Smith and Russo, 2014)).

The geomatic process estimated that towns across the six countries on average had a range of average population densities with Flemish towns exhibiting the lowest population densities (around 1100 persons per square $\mathrm{km}$ ) and English and Welsh towns recording the highest average population density (around 1600 persons per square $\mathrm{km}$ ). The process of intersection with small area attribute geographies allows us to estimation demographic and labour market characteristics of these towns. The geospatial characteristics of the boundary polygons allow us to calculate context characteristics such as how far the town is located from a major settlement or whether the town is located near a coast (for example).

[Table 3 about here]

For demographic and labour market characteristics, Table 3 sets out the sources of the small area data that was aggregated to the town boundaries. The small area data was sourced from the National Statistics Institute in each country. For demographic data the principal source was small area census data obtained for a census at the beginning and at the end of the 2000s (the base and end years). Data on births and deaths was also obtained from the 
National Statistics Institute (NSI) from administrative data collected on the same geographic units as the census data in each case. In this way the data was collected for a comparable part of the year in each case (although not necessarily the same for all countries). In the case of Slovenia, the shortened period of 2001-2007 was adopted because there was a major spatial reorganisation of local government boundaries in $2007 / 08$. Thus the small area data between 2001 and 2007 could be compared on the basis of it being derived from the same set of geographic units.

In order to estimate workplace-based employment data for the towns, small area data on workplace employment was also obtained from the relevant National Statistics Institute for each country. The time periods available for workplace-based data were less harmonised than the case of demographic data as observed in Table 3. Thus when measuring changes between a base and an end year, the procedure of annualising has been adopted whereby any calculated change is divided by the period between the end and base years.

In this way a database could be constructed for 1978 towns across the six countries for two years across a decennial census period. As well as basic demographic data (total population and the counts of births and deaths) data could be assembled in relation to age, labour market status and housing where this data is collected as part of a national census exercise. The six countries offer a range of contexts by which to compare changes in towns in the 2000s. The national cases range from densely populated and urbanised countries such as the United Kingdom and Belgium to sparsely population contexts such as Sweden. France offers a wide range of contexts for small towns ranging from metropolitan to rural areas. In addition to this there are two East-Central European countries.

[Table 4 about here]

Thus it is possible to construct an attribute data-set for towns with a population between 5,000 and 50,000 bringing together the morphologically defined settlement boundaries and the small area administrative data-sets that are harmonised within the European Union. Having constructed such a data-set for our six national urban systems, the question arises as to what to do with them. 


\section{Method}

The paper poses two questions: firstly, have towns in different national systems undergone different types of demographic change between 2001 and 2011? Secondly, can differences in demographic change in towns be better explained in relation to their regional (subnational) context or are patterns of demographic change best explained with reference to the country in which the town is located? The evidence will be presented in two stages. Firstly, ANOVA analysis will be used to establish whether demographic change in towns varies significantly between different national urban systems. ANOVA analysis will be combined with post hoc tests to establish any significant differences between countries. Secondly, evidence will be presented from multi-level regression analysis that has been applied to our complete data-set of towns (as a general model). As well as analysing the complete data-set of towns, multi-level regression analysis has also been applied to national sets of towns (in Britain and France) to compare nation-specific analysis with the general model.

\section{ANOVA analysis}

ANOVA analysis has been applied to three different measures of demographic change: change in total population, natural change in population (the balance of births and deaths) and net migration change (based on a residual population model). Country is used as the discriminating variable between the towns and Table 5 presents the basic descriptive data for such an analysis. Table 5 suggests that there were significant differences in the patterns of demographic change in towns between the different national urban systems in the dataset. Over the period of study, the data suggests that French towns experienced an average natural change of 2.63 persons per 1000 residents. This was very different from towns in the other four national urban systems where average natural change varied from -0.57 persons per 1000 (England and Wales) to 1.21 persons per 1000 (Belgium). Looking at the figures for net migration there is a very large difference between towns in England and Wales (averaging 7.19 persons per 1000 net migration) and towns in the Czech Republic (averaging 0.44 persons per 1000).

[Table 5 about here]

[Table 6 about here]

Table 6 presents the omnibus analysis of differences between the means of towns from different national urban systems. In all cases the Welch statistic is statistically significant indicating that at least one group of towns has a significantly different mean to other groups of towns. The difference is most significant for natural population change. In Table 6, the effect size, $\omega$ indicates that the relationship between these measures of demographic change and nationality are medium-strength effects (after Cohen 1968).

The group by group comparison using the Games-Howell procedure confirms that Czech towns (as a group) are statistically significantly different in terms of overall population change from all other national urban systems on all three measures. On this omnibus measure of difference there is a notable split between the Western European urban 
systems (England and Wales, France, Belgium and Sweden) and the East-Central European urban systems (Slovenia and the Czech Republic). The differences in average natural population change between French towns and the rest and the differences in net migration rates between English and Welsh towns and the rest (described in Table 5) are found to be significant using the post hoc testing procedure. Based on this ANOVA testing, national context appears to be important in differentiating demographic change in towns. The question arises as to what might be explained relative to the town attributes within national urban systems.

\section{Multi-level regression model}

The literature clearly conceptualises the importance of the wider spatial context for towns (either national or regional). The ANOVA analysis above based on national context alone only explains four to nine per cent of the variance on the three measures of demographic change in towns. Yet towns are not only framed by their location within their national urban system. Hinderink and Titus (2002) also point to the significance of regional (subnational) context for town development. In order to specify a regression model that captures the hierarchical context for towns, the paper proposes a two level regression model seeing the relationship as a nested hierarchy. This implies that town performance is likely to be influenced by the regions in which they are located to a greater degree than by the performance of places that are close to them (which would imply a spatial regression model). In this paper NUTS2 regions are used as the regional level. Xu (2014) compares the insights of spatial and multi-level regression modelling and notes that the capacity of standard multi-level regression and pure spatial models are similar in producing estimates in a fixed effect model. Given our interest in the general regional context for towns and the similarity of performance between the two model specifications, we have deployed the multi-level specification.

The proposed multi-level specification will predict demographic growth (measured as either net migration rate or natural change rate). The predictor (or independent) variables are identified at two levels: that of the town and that of the NUTS2 region. The general specification is given in equations 1 to 3 . In linear form (equation 1 ), the dependent variable for town $i$ in region $j$ is made up of a constant to be estimated, $b_{0 i j}$ that is itself calculated from equation (2). The model is a fixed effects model and thus each $B_{0 i j}$ is specific to the region $j$. The model effectively divides the variance in the residuals $\sigma$ between a town effect $e_{o i j}$ (within region variance) and a regional effect $u_{0 j}$ (between region variance). The goodness of fit is estimated for an iterative generalised least squares process (IGLS) is made on the basis of a log likelihood calculation for each step in the analysis.

$$
\begin{aligned}
& y_{\text {town,region }}= \beta_{0 \text { region }} x_{0}+\beta_{1} x_{1 \text { region }}+\beta_{2} x_{2 \text { town,region }} \\
& \beta_{0 \text { region }}=\beta_{0}+u_{\text {oregion }} \\
& {\left[u_{\text {oregion }}\right] \sim N\left(0, \sigma_{u}\right):\left[e_{\text {town,region }}\right] \sim N\left(0, \sigma_{e}\right) }
\end{aligned}
$$

The variables for the model will be based on a structured path in acknowledgement of potential endogeneity within these concepts. The attribute values for the town 
(demography, labour market and amenity value) at both town and regional levels relate to the base year in the data-set. The dependent variable (the measure of demographic change) relates to the change recorded between the base year and the end year for the town.

In order to capture the existing demographic structure of the town, the model includes measures of the proportion of children aged 14 years and younger and the proportion of adults aged 65 years and over. These are used to capture whether the town is already a site of retirement within its urban system or indeed whether the town's population has a population that is youthful. Labour market characteristics are captured by the proportion of working age adults who are economically active (in forms of employment and unemployment). The nature of the town as a site for employment (and inward commuting) is captured by the ratio of working age adults who are in employment to the workplacebased estimate of people who work in the town (as the ratio gets larger, the more the town appears to be a dormitory settlement where people live but work somewhere else). In the tables this variable is labelled the dormitory indicator. Amenity value is captured through a dummy variable recording whether the town is within $5 \mathrm{~km}$ of the coastline since coastal towns might expect to record in-migration especially amongst older age groups (retirement towns). Equally the distance of each town from its nearest large city (with a population greater than 50000) is included in order to capture any spread or backwash effects. In addition to these variables the statistical analysis will include population size as a control following the work of Congdon and Shepherd (1986) who used population size to control for error effects relating to the calculation of the attribute values for small settlements (through aggregating small area data).

The paper's hypothesis is centred on demonstrating that demographic change in towns is influenced by the dynamics of the region in which it is located over and above the particular characteristics of a town alone. In the general model dummy variables will be used for each national system leaving the United Kingdom as the reference category. In the multi-level analysis the aim is to capture the internal regional variation for the larger national urban systems (France and the United Kingdom). Thus the model will work with NUTS2 regions as our proxy for the wider functional region into which our towns are located. Based on Table 4 it is clear that an individual town constitutes (on average) under $1 \%$ of the population for the NUTS2 region in which it is located. Each town constitutes such a small proportion of its region, we might expect the change in regional population to be reasonably independent of any population change within an individual town. Thus the model will take annualised regional population growth as an explanatory variable.

In order to capture amenity value, the model includes a dummy variable for being located within $5 \mathrm{~km}$ of the coast. Favourable climate is captured using the tourism comfort index (TCl). The $\mathrm{TCl}$ is a complex indicator incorporating data on sunshine hours, temperature and rainfall (see Mieczkowski 1985). We have taken the difference in average TCls for summer months and winter months as an indicator of climate of warm summers and mild winters (on average). In tourism terms a small $\mathrm{TCl}$ difference indicates a longer potential tourism season. 
Models were run on the two different components of demographic change: annualised natural population change and the annualised net migration rate. Both were calculated between the base and end year of the data set whilst the attribute characteristics of the town were calculated for the base year. Models were run both as a multi-level model over 66 NUTS2 regions and 1769 towns in five national urban systems. The models were also run as a single level linear model (to check for the effects of multi-collinearity). For both the annual rate of natural population change and for the annual net migration rate the specified models improved the prediction of the dependent variables by the log likelihood-ratio test (see Table 7). The regression coefficients for these models are set out in Table 7 giving the unstandardized coefficient and the standard error of the estimate of the unstandardized coefficient. All the coefficients with the exception of the distance variable have been calculated assuming independent variables that have been centred to a grand mean of all the towns. Towns from England and Wales have been taken as the reference category.

[Table 7 about here]

[Table 8 about here]

The coefficients in Table 8 confirm the importance of the national context. All the national dummy variables are referenced to the case of England and Wales (the UK). Towns in the Czech Republic and Slovenia record higher net migration rates than might be expected taking all other components of the model into account. By contrast French towns record lower net migration rates taking the rest of the model into account. However the regional population change is also significant for the prediction of both net migration rates and the rate of natural population change. Towns in regions with smaller inter-seasonal differences record higher levels of net migration than towns with wider inter-seasonal differences (as recorded by the $\mathrm{TCl}$ ). These regional level variables significantly reduce the variance partition coefficient (VPC) related to the regional level comparing the VPC for no predictors and the VPC with predictors.

In the general model, at the level of the town most of the independent variables are significantly related to the dependent variables (demographic change variables) with signs that are broadly expected. In relation to predicting net migration rates, both the proportion of children (aged under 15 years) and older residents (65 years and over) are significantly and positively related to net migration rates. Labour market conditions are importantly related to net migration rates in that towns with higher employment rates and towns that appear to be strong dormitory locations also record higher rates of net migration. Finally location is important for towns in that a coastal location is associated with a large positive fixed effect for net migration. On the other hand distance from a larger city has a negative impact on net migration with net migration rates predicted to decrease as the distance from a large city increases.

The annualised natural rate of population change in towns is also positively related to high employment rates (for residents) and being a dormitory centre (as recorded by the ratio of residents in employment to workplace-based employment). As might be expected natural change rates are positively associated with a greater proportion of children already resident in the town and negatively associated with a greater proportion of older residents (in the 
base year). However the geographic context of being close to a city or being located at the coast does not have a statistically significant impact on natural population change rates.

In order to consider whether this general model holds for individual national urban systems the model was run on the national systems of France and of England and Wales taking the net migration rate as the dependent variable. It was not possible to do this exercise for Flanders (Belgium), Slovenia or the Czech Republic because there were too few NUTS2 regional units for these countries. Table 9 outlines the estimates of the regression parameters for England and Wales (combined) and for France. This exercise reveals that towns either within England and Wales or within France exhibit some quite different statistical relationships. The common features of the two systems are that net migration rates are strongly associated with towns with a greater proportion of pension-age residents. There is a strong relationship with milder climates (indicated by smaller inter-seasonal TCI differences) in France. There is a weaker relationship for England and Wales (borderline significance).

[Table 9 about here]

For the most part the French towns mirror the general model set out in Table 8 although distance from a larger city was insignificant in the case of the French town model. In the case of England and Wales, most of the indicator that were significant in the general model become insignificant. So labour market conditions do not appear to relate to net migration rates and there is no relationship between population growth at NUTS2 level and at the level of the town in the case of England and Wales. However distance from a major city is highly significant indicating that in the case of England and Wales it is the most rural towns (and potentially the least accessible) that have experienced the highest levels of net inmigration. Thus whereas we can estimate a general model across national urban systems, it is also clear that there may be important differences between national systems that are captured in the general model through the fixed effect component. This suggests that there we have two distinct models for demographic growth in towns: a French model and a British model. English and Welsh towns appear to exhibit a developmental profile that is less dependent upon the economic function of the town than is the case in France. These nation-specific features are hidden by the fixed effect component in the general model applied across national systems.

\section{Discussion}

The paper set out to explore statistically whether there is a common model for population growth for towns across national settlement systems in Europe. The analysis is based on a new data-set for towns based on aggregating harmonised small area data and a common morphological definition of what constitutes a town. The evidence suggests that for the period of the 2000s, there remained statistically significant differences in demographic changes between towns across the national urban systems included in this analysis. Whereas in all countries covered, net migration appears to be the most significant process of demographic change, the relative importance of natural change versus net migration vary significantly between national systems. French towns appear to be growing through natural change more than in other urban systems whilst English and Welsh towns appear to be 
growing through net migration at much higher rates than in other urban systems. Czech towns appear to be growing the least on average.

In applying a general multi-level regression model based on nesting towns within their NUTS2 region and applying national dummy variables. This general model confirms the basic predictors of demographic change in towns - this general model suggests that towns experience higher net migration rates if they have an older population, are close to larger cities, are dormitory locations and have amenity value (mild climate and coastal location). This would be consistent with the 'spread effects' observed by Partridge et al (2007) within the Canadian urban system. Within this general model regional population change is a very strong predictor of demographic change in towns suggesting that towns have a limited capacity to grow when their region might be shrinking (for example).

When the general model is applied to British (England and Wales) and French urban systems separately, it is clear that the general model does not hold. In this particular case, French towns appear to follow a 'general model' but English and Welsh towns appear to follow a different pattern. Whereas the presence of an older population and the amenity value of a mild climate hold, for English and Welsh towns, being further away from larger cities appears to be a more important predictor of demographic growth. The question arises as to whether urban systems for larger countries (such as Germany or Poland) might follow the general model or whether they might further fragment the pattern confirming the notion of distinctive national models for development in towns.

The overall hypothesis of whether (sub-national) regional context frames demographic growth is not proven conclusively by this analysis given the differences between the general model and the nation-specific models. In the general multi-level model the regression coefficients suggest that regional growth is a very good predictor of demographic change at the level of a town. The potential mechanism for growth is through net migration and through high levels of employment (within the wider region). Towns with a higher proportion of working age adults in employment grow faster but dormitory towns grow faster than employment centre towns in the general model. However, when breaking the analysis down urban system by urban system the framing capacity of regional growth is not clear. Certainly within England and Wales the evidence suggests that NUTS2 population growth is not a useful predictor of demographic change in towns. In contrast the model for French towns suggests that regional growth is a useful predictor of net migration rate. This analysis has not attempted to consider whether re-drawing the regional geography for English and Welsh towns into a functional geography determined by commuting patterns for example would produce a regional framing effect.

Such work only gets us so far. This simple modelling has not been able to consider the age profile of in-migration to towns and has not been able to examine the nature of employment (for example by industrial sector) on changes in towns. Equally the use of net migration based on a residual population model is problematic. Ideally a direct measure of net migration would be better. The concept of amenity has been included by the means of a town's location (either close to the coast or close to a city) but this first run of analysis does not have more sophisticated measures of amenity quality. Work by Knox and Mayer (2009) has opened up interesting avenues (in terms of case study evidence) but these 
insights need to be tested and systematised across different national urban systems. The current analysis is further restricted by taking the proxy of population change as the measure of success in towns rather than economic measures of growth (such as jobs or output).

This is work that needs to develop further datasets relating to housing markets and housing availability in towns since it has not been possible in this paper. Equally there is a need to explore in greater depth the inter-relationship of employment and population change. Given the data assembled here, the paper has not explored year on year changes in population and employment change in order to investigate whether there is a time lag effect between these two types of change. This would be important in order to distinguish between employment-led demographic growth and consumption-led employment growth in towns.

This paper has made towns a little less invisible although it has only scratched the service of the roles that towns play within the European and national urban systems.

References

BRETAGNOLLE, A., MATHIAN, H., PUMAIN, D. and ROZENBLAT, C., 2000. Long-term dynamics of European towns and cities: towards a spatial model of urban growth. Cybergeo: European Journal of Geography.

BRUNET, R., 1997, "Villes moyennes: point de vue de géographe", in Commerçon, $\mathrm{N}$ and Goujon P. (eds), Villes moyennes: espaces, société, patrimoine, Presses Universitaires de Lyon, Lyon, pp. 13-25.

CHAMPION, T. and SHEPHERD, J., 2006. Demographic change in rural England. The ageing countryside: The growing older population of rural England, pp. 29-50.

COHEN, J., 1968. Multiple regression as a general data-analytic system. Psychological Bulletin, 70(6p1), p.426.

CONGDON, P. and SHEPHERD, J., 1986. Modelling population changes in small English urban areas. Environment and Planning A, 18(10), pp. 1297-1322.

GOSNELL, H. and ABRAMS, J., 2011. Amenity migration: diverse conceptualizations of drivers, socioeconomic dimensions, and emerging challenges. GeoJournal, 76(4), pp.303322.

HALL, P.G. and HAY, D., 1980. Growth centres in the European urban system. Univ of California Press.

HINDERINK, J. and TITUS, M., 2002. Small Towns and Regional Development: Major Findings and Policy Implications from Comparative Research. Urban Studies, 39(3), pp. 379-391. 
KNOX, P. and MAYER, H., 2009. Small town sustainability: Economic, social, and environmental innovation. Walter de Gruyter.

MARIO, C. and CHRISTOPHE, D., 2012. La socio-économie des villes petites et moyennes: questions théoriques et implications pour l'aménagement du territoire. Revue d'économie régionale et urbaine, 2(4), pp. 135-149.

MATLOVIC, R. and BERNASOVSKY, I., 2003. Selected demographical features of Slovak small cities, L'avenir des petites villes: actes du colloque international de Clermont-Ferrand, 20 et 21 novembre 2002 2003, Presses Univ Blaise Pascal, pp. 43.

MIECZKOWSKI, Z., 1985. The tourism climatic index: a method of evaluating world climates for tourism. The Canadian Geographer 29, pp. 220-33.

MYRDAL, G., 1963. Economic Theory and Underdeveloped Regions. London: Methuen and Co, Ltd.

PARTRIDGE, M., BOLLMAN, R.D., OLFERT, M.R. and ALASIA, A., 2007. Riding the wave of urban growth in the countryside: spread, backwash, or stagnation? Land Economics, 83(2), pp. 128-152.

POWE, N.A., HART, T., and BEK, D., 2009. Market town centres in England: meeting the challenge of maintaining their contemporary relevance. Planning, Practice \& Research 24(3), pp. 301-319.

RENAUD-HELLIER, E., 2003, Attraction périurbaine et petites villes « de marge » : l'exemple dijonnais, in L'avenir des petites villes, pp. 61-79, Actes du colloque international de Clermont-Ferrand, CERAMAC 21 novembre 2002, Presses Universitaires de ClermontFerrand, 325p.

RUSSO, A.P., forthcoming. Identifying and classifying small and medium sized towns in Europe, Tijdschrift voor Economische en Sociale Geografie.

SHEPHERD, J., 2009. A Typology of the Smaller Rural Towns of England

SMITH, I. and RUSSO, A., 2014. Building a database of morphological towns. In SERVILLO, L. (ed.) TOWN: Small and medium sized towns in their functional territorial context - Scientific Report to Applied Research 2013/1/23. Chapter 3. ESPON \& KU Leuven, 2014.

TERLUIN, I.J., 2003. Differences in economic development in rural regions of advanced countries: an overview and critical analysis of theories. Journal of Rural Studies, 19(3), pp. 327-344.

VAN LEEUWEN, E.S. and RIETVELD, P., 2011. Spatial consumer behaviour in small and medium-sized towns. Regional Studies, 45(8), pp. 1107-1119.

XU, H., 2014. Comparing Spatial and Multilevel Regression Models for Binary Outcomes in Neighborhood Studies. Sociological methodology, p.0081175013490188. 
Table 1: Characteristics of the small area statistical units used in different European countries

\begin{tabular}{|c|c|c|c|c|c|c|}
\hline \multirow[b]{2}{*}{ Country } & \multirow[b]{2}{*}{ type } & \multirow{2}{*}{$\begin{array}{c}\text { number } \\
\text { of small } \\
\text { areal } \\
\text { units }\end{array}$} & \multicolumn{2}{|c|}{ population 2001} & \multicolumn{2}{|c|}{ area (ha) } \\
\hline & & & mean & $\begin{array}{c}\text { coeff of } \\
\text { variation }\end{array}$ & mean & $\begin{array}{c}\text { coeff of } \\
\text { variation }\end{array}$ \\
\hline Belgium & municipality & 589 & 17,481 & 1.57 & 5,183 & 0.73 \\
\hline Czech Republic & municipality & 6,258 & 1,635 & 10.35 & 1,260 & 1.31 \\
\hline France & municipality & 36,677 & 1,641 & 8.52 & 1,726 & 8.53 \\
\hline Sweden & municipality & 289 & 30,736 & 1.89 & 142,192 & 1.75 \\
\hline Slovenia & municipality & 192 & 10,229 & 2.13 & 10,560 & 0.90 \\
\hline England \& Wales & statistical output area & 34,378 & 1,514 & 0.13 & 439 & 3.36 \\
\hline
\end{tabular}

Table 2: Characteristics of the intersection between geomatic polygon boundaries (for towns) and the small area geographies associated with attribute data

\begin{tabular}{|c|c|c|c|c|c|c|}
\hline & \multicolumn{2}{|c|}{ No of towns in: } & \multicolumn{2}{|c|}{ For geomatic polygons } & \multirow[b]{2}{*}{$\begin{array}{c}\text { average } \\
\text { number of } \\
\text { SAS/LAU } \\
\text { units per } \\
\text { polygon }\end{array}$} & \multirow[b]{2}{*}{$\begin{array}{l}\text { Mean small } \\
\text { area } \\
\text { estimate of } \\
\text { population } \\
\text { (base year) }\end{array}$} \\
\hline Country & $\begin{array}{c}\text { In geomatic } \\
\text { database }\end{array}$ & $\begin{array}{l}\text { covered by } \\
\text { areal data }\end{array}$ & $\begin{array}{c}\text { Mean } \\
\text { estimated } \\
\text { population } \\
\text { of } \\
\text { settlement } \\
2006 \\
\end{array}$ & $\begin{array}{l}\text { Mean area } \\
\text { of } \\
\text { settlement } \\
(\mathrm{km} 2)\end{array}$ & & \\
\hline Belgium (Flanders) & 158 & 120 & 12,801 & 12.18 & 2.29 & 12,600 \\
\hline Czech Republic & 217 & 216 & 13,136 & 8.29 & 2.90 & 12,603 \\
\hline France & 858 & 835 & 12,182 & 9.14 & 3.47 & 11,092 \\
\hline Slovenia & 41 & 41 & 11,082 & 9.10 & 1.12 & 10,891 \\
\hline Sweden & 189 & 189 & 12,768 & 10.39 & 1.51 & 12,187 \\
\hline $\begin{array}{l}\text { United Kingdom } \\
\text { (England and Wales) }\end{array}$ & 691 & 577 & 14,652 & 9.08 & 12.32 & 11,464 \\
\hline
\end{tabular}

Table 3: Data sources for small area data

\begin{tabular}{|l|c|c|c|c|c|c|}
\hline & \multicolumn{3}{|c|}{ demographic data } & \multicolumn{3}{c|}{ workplace-based data } \\
\hline Country & source & $\begin{array}{c}\text { base } \\
\text { year }\end{array}$ & $\begin{array}{c}\text { end } \\
\text { year }\end{array}$ & source & $\begin{array}{c}\text { base } \\
\text { year }\end{array}$ & $\begin{array}{c}\text { end } \\
\text { year }\end{array}$ \\
\hline Belgium (Flanders) & NSI & 2001 & 2011 & NSI & 2001 & 2010 \\
\hline Czech Republic & NSI & 2001 & 2011 & NSI & 2001 & 2011 \\
\hline France & NSI & 1999 & 2010 & NSI & 1999 & 2010 \\
\hline Slovenia & NSI & 2001 & 2007 & NSI & 2001 & 2007 \\
\hline Sweden & NSI & 2001 & 2011 & NSI & 2004 & 2011 \\
\hline United Kingdom (England and Wales) & NSI & 2001 & 2011 & NSI & 2003 & 2010 \\
\hline
\end{tabular}


Table 4 outlines the descriptive data from this database.

\begin{tabular}{|l|c|c|c|c|}
\hline & Mean & SD & $\begin{array}{c}\text { Coeff } \\
\text { of var'n }\end{array}$ & Skew \\
\hline $\begin{array}{l}\text { distance (in km) of settlement centroid to nearest } \\
\text { larger city (with more than 50,000 inhabitants) }\end{array}$ & 20 & 25 & 1.22 & 4.21 \\
\hline $\begin{array}{l}\text { proportion of NUTS2 population accounted for by } \\
\text { small town }\end{array}$ & 0.64 & 0.71 & 1.11 & 4.31 \\
\hline $\begin{array}{l}\text { annualised observed change in population per } \\
1000 \text { population in base year }\end{array}$ & 6.34 & 9.03 & 1.43 & 1.21 \\
\hline $\begin{array}{l}\text { annualised natural change in population per 1000 } \\
\text { population in base year }\end{array}$ & 1.31 & 4.18 & 3.18 & -0.30 \\
\hline $\begin{array}{l}\text { annualised net migration rate per 1000 } \\
\text { population in base year }\end{array}$ & 5.02 & 8.88 & 1.77 & 0.90 \\
\hline
\end{tabular}

Table 5: Descriptive statistics on demographic change for towns

\begin{tabular}{|l|c|c|c|c|}
\hline & $\begin{array}{c}\text { annualised } \\
\text { observed } \\
\text { change in } \\
\text { towns } \\
\text { population } \\
\text { per } 1000 \\
\text { population } \\
\text { in base year }\end{array}$ & $\begin{array}{c}\text { annualised } \\
\text { natural } \\
\text { change in } \\
\text { population } \\
\text { per } 1000 \\
\text { population } \\
\text { in base year }\end{array}$ & $\begin{array}{c}\text { annualised } \\
\text { net } \\
\text { migration } \\
\text { rate per } \\
1000 \\
\text { population } \\
\text { in base year }\end{array}$ \\
\hline Belgium (Flanders) & 120 & 5.76 & 1.21 & 4.56 \\
\hline Czech Republic & 216 & 0.56 & 0.12 & 0.44 \\
\hline France & 835 & 6.44 & 2.63 & 3.81 \\
\hline Sweden & 189 & 5.41 & 0.66 & 4.75 \\
\hline Slovenia & 41 & 3.37 & 0.02 & 3.34 \\
\hline United Kingdom (England and Wales) & 575 & 6.62 & -0.57 & 7.19 \\
\hline
\end{tabular}


Table 6: ANOVA results for demographic change in towns across five urban systems

\begin{tabular}{|l|c|c|c|c|}
\hline & $\begin{array}{c}\text { Welch } \\
\text { statistic }\end{array}$ & $\left(\mathrm{df}_{1}, \mathrm{df}_{2}\right)$ & $\begin{array}{c}\text { sig (of } \\
\text { Welch } \\
\text { statistic) }\end{array}$ & $\begin{array}{c}\text { effect } \\
\text { size, } \omega\end{array}$ \\
\hline $\begin{array}{l}\text { annualised observed change in population } \\
\text { per } 1000 \text { population in base year }\end{array}$ & 26.67 & $(5,312)$ & 0.000 & 0.21 \\
\hline $\begin{array}{l}\text { annualised natural change in population per } \\
1000 \text { population in base year }\end{array}$ & 58.47 & $(5,306)$ & 0.000 & 0.36 \\
\hline $\begin{array}{l}\text { annualised net migration rate per } 1000 \\
\text { population in base year }\end{array}$ & 31.52 & $(5,316)$ & 0.000 & 0.24 \\
\hline
\end{tabular}

Table 7: Model summaries for two-level regression models on demographic change

\begin{tabular}{|l|c|c|}
\hline & $\begin{array}{c}\text { annual } \\
\text { net } \\
\text { migration } \\
\text { rate }\end{array}$ & $\begin{array}{c}\text { annual } \\
\text { natural } \\
\text { change } \\
\text { rate }\end{array}$ \\
\hline$-2^{*}$ loglikelihood (model with no predictors)' & 12673.4 & 9817.2 \\
\hline$-2^{*}$ loglikelihood (model with predictors)' & 11866.6 & 7102.3 \\
\hline Variance partition coefficients (no predictors) for regional variance $^{\prime}$ & 0.34 & 0.40 \\
\hline Variance partition coefficients (with predictors) for regional variance $^{\prime}$ & 0.04 & 0.25 \\
\hline Number of NUTS2 regions in analysis & 66 & 66 \\
\hline Number of towns in analysis & 1763 & 1763 \\
\hline
\end{tabular}

Table 8: Coefficients on explanatory variables for two-level regression models on demographic change

\begin{tabular}{|l|c|c|c|c|c|c|}
\hline & \multicolumn{3}{|c|}{$\begin{array}{c}\text { annual net migration } \\
\text { rate }\end{array}$} & \multicolumn{3}{c|}{$\begin{array}{c}\text { annual natural } \\
\text { change rate }\end{array}$} \\
\hline & B & S.e. & & B & S.e. & \\
\hline Constant (UK reference category) & 5.97 & 0.661 & $* *$ & 0.71 & 0.156 & $* *$ \\
\hline Dummy variable for Belgium & 3.20 & 1.259 & $* *$ & 1.27 & 0.289 & $* *$ \\
\hline Dummy variable for Czech Rep & 2.91 & 1.405 & $* *$ & -2.34 & 0.320 & $* *$ \\
\hline Dummy variable for France & -2.39 & 0.764 & $* *$ & 1.20 & 0.168 & $* *$ \\
\hline Dummy variable for Slovenia & 3.21 & 1.770 & $*$ & -1.38 & 0.408 & $* *$ \\
\hline Regional population change 2001-11 & 0.83 & 0.095 & $* *$ & 0.11 & 0.021 & $* *$ \\
\hline Inter-seasonal Tourism Comfort Index & -0.69 & 0.151 & $* *$ & 0.02 & 0.033 & \\
\hline Prop. of town population aged under 15 & 0.43 & 0.137 & $* *$ & 0.33 & 0.036 & $* *$ \\
\hline Prop. of town population aged >65 years & 0.75 & 0.083 & $* *$ & -0.61 & 0.022 & $* *$ \\
\hline Employment rate (of working age adults) & 0.21 & 0.042 & $* *$ & 0.03 & 0.011 & $* *$ \\
\hline Dormitory town indicator & 0.01 & 0.003 & $* *$ & 0.00 & 0.001 & $* *$ \\
\hline Standardised population size of town & -0.67 & 0.172 & $* *$ & 0.31 & 0.045 & $* *$ \\
\hline Log of distance from large city & -0.51 & 0.187 & $* *$ & 0.05 & 0.048 & \\
\hline Dummy variable for coastal location & 2.16 & 0.526 & $* *$ & -0.21 & 0.136 & \\
\hline
\end{tabular}


Table 9: Coefficients from multilevel regression on UK and French towns

\begin{tabular}{|l|c|c|c|c|c|c|}
\hline & \multicolumn{3}{|c|}{$\begin{array}{c}\text { Net migration rate for } \\
\text { UK towns }\end{array}$} & \multicolumn{3}{c|}{$\begin{array}{c}\text { Net migration rate for } \\
\text { French towns }\end{array}$} \\
\hline & B & S.e. & & B & s.e. & \\
\hline Constant (non-coastal) & 4.24 & 0.745 & $* *$ & 4.29 & 0.838 & $* *$ \\
\hline Inter-seasonal Tourism Comfort Index & -0.41 & 0.241 & $*$ & -0.61 & 0.169 & $* *$ \\
\hline Regional population change 2001-11 & 0.07 & 0.169 & & 1.11 & 0.123 & $* *$ \\
\hline Standardised population size of town & -0.26 & 0.280 & & -0.98 & 0.277 & $* *$ \\
\hline Log of distance from large city & 1.55 & 0.328 & $* *$ & -0.35 & 0.283 & \\
\hline Dummy variable for coastal location & -0.38 & 0.725 & & 3.20 & 0.812 & $* *$ \\
\hline Prop. of town population aged under 15 & 0.27 & 0.261 & & 0.48 & 0.189 & $* *$ \\
\hline Prop. of town population aged >65 years & 0.64 & 0.143 & $* *$ & 0.72 & 0.127 & $* *$ \\
\hline Employment rate (of working age adults) & 0.03 & 0.077 & & 0.29 & 0.057 & $* *$ \\
\hline Dormitory town indicator & -0.01 & 0.005 & & 0.04 & 0.005 & $* *$ \\
\hline
\end{tabular}

